\title{
Registration of radar and optical satellite images using multiscale filter technique and information measure
}

\author{
Qi Li ${ }^{1}$, Bihong $\mathrm{Fu}^{2}$ and Yanfang Dong ${ }^{3}$ \\ ${ }^{1}$ National Institute of Advanced Industrial Science and Technology (AIST) \\ Japan \\ 2Institute of Geology and Geophysics, Chinese Academy of Sciences \\ China \\ ${ }^{3}$ Institute of Earthquake Science, China Earthquake Administration
}

China

\section{Introduction}

Since a spectacular series of missions in the context of the Earth Observing System (EOS) by NASA beginning from the late 1990's, the significance of the satellite remote sensing has been recognized all over the world (Kafatos \& Qu, 2007; Kaufman et al., 1998). In particular, the applications on hazard mitigation and resource exploration have been widely regarded as one of basic approaches over the past years (e.g., Barrett et al., 1991; Chuvieco, 2008; Fu et al., 2004; Ninomiya et al., 2005; 2006; Realmuto, 2000; Sato et al., 2006; Teeuw, 2007; Urai et al., 2007). In general, remote sensing, from different points of view, includes many branches, or exactly speaking many application fields, such as environmental and ecological remote sensing, geological remote sensing, and military remote sensing. In this chapter, we focus our research on geological applications. However, the proposed algorithms and approaches might be applicable to every fields associated with image registration processing. Although remotely sensed optical images from satellite sensors can meet most needs in the practical applications, considerable weather-dependence limits its functional deployment under some circumstances. For instance, during the period of the devastating Ms 8.0 Wenchuan earthquake in the summer of 2008 (Fu et al., 2009), the most optical images from ASTER (Advanced Spaceborne Thermal Emission and Reflection Radiometer) (Yamaguchi et al., 1998) sensors on the NASA's Terra satellite can hardly be used to do some refined applications just because of heavy clouds contaminated. However, SAR (Synthetic Aperture RADAR) images are not influenced by climate and time. In practical applications, the optical satellite images, in particular with high resolutions from sensors such as SPOT (Chevrel et al., 1981) and IKONOS (Tanaka \& Sugimura, 2001), provides excellent legibility, but they may be affected by the clouds and weather conditions. On the other hand, SAR images are not influenced by climate and they can be obtained day-and-night, but they suffer from a serious intrinsic speckle noise (Franceschetti \& Lanari, 1999; Lampropoulos \& Boulter, 1997). 
Therefore, the joint application of these two different kinds of data information will be great interest for many geological problems associated with the remote sensing (e.g., Chen et al., 2003). The first major processing for such a combination is to finish an accurate registration. That is why registration of images coming from different sources is of increasing importance (Le Moigne et al., 2002; Li, 2006; Li et al., 2006c; Li et al., 2008; Schowengerdt, 2006).

Up to now, many registration methods have been proposed to register SAR and optical satellite images manually or (semi-)automatically (e.g., Ali \& Clausi, 2002; Cheng et al., 2004; Curlander \& Kober, 1990; Dare \& Dowman, 1996; 2001; Galland et al., 2005; Hong \& Schowengerdt, 2003; 2005; Inglada \& Vadon, 2005; Lampropoulos et al., 2003; Lampropoulos et al., 2002; Li et al., 1993; 1995; Li et al., 2007c; Mao et al., 2007; Raucoules \& Carnec, 1999; Shu \& Tan, 2007; Shu et al., 2005; Thepaut et al., 1998; Vornberger \& Bindschadler, 1992; Wang \& Chen, 2003; Wegner \& Soergel, 2008a; 2008b; Wu \& Maitre, 1990; Yang et al., 2005; Zamora et al., 1998; Zhang et al., 2007; Zhang et al., 2004; Zhao \& Chen, 2003). In general, these methods can be classified into two major categories: feature based method and intensity based method ( $\mathrm{Li}$ et al., 2006c). The feature based registration method has been widely implemented into the commercial software, such as ENVI and ERDAS Imagine, initially for the mono-modality image registration, but it encounters significant difficulties when to-be-matched features are not easily extracted from different source images. For example, it is very difficult to extract the features (e.g., roofs and crossroads) from ASTER image for very rural area (e.g., Horonobe, Hokaido, Japan) rather than for metropolitan area (e.g., Tokyo). Furthermore, for the radar image (e.g., RADARSAT-2), this difficulty becomes even heavier than the optical images. Therefore, the corner reflector is often needed to install on the ground so as to enhance the accurate registration process ( $\mathrm{Li}$ et al., 2009). On the other hand, the intensity based registration method may be easily implemented as a semi- or fully automatic manner, but it is seriously dependent on the choice of similarity measures or metrics, and usually needs large amount of computation (Inglada \& Giros, 2004).

Due to the distinct and intrinsic differences of imaging properties between radar and optical images, it is not easy to extract corresponding features from them. Moreover, serious speckle noise existing in radar images further aggravates this problem. Thus, it is a very challenging problem to precisely and automatically register them with a satisfactory accuracy. Wu \& Maitre (1990) proposed multiresolution approach to register the SPOT-XS and SEASAT SAR images by matching the contour lines in different scale space representations, but the problems of no distinct features in SAR images still remain. Vornberger \& Bindschadler (1992) conducted multispectral research of ice sheets over an area of Greenland by registering Landsat TM and SAR imagery. They found that significant corrections to the SAR data were required to account for range-darkening, non-square pixel dimensions, speckle, and relief distortion. The exposed rock was available to be used as corresponding control points in one area, while it was absent in another area and lakes and streams were used. Li et al. (1993) used an elastic active contour to register the optical and SAR images. Using the contours from the optical image as the initial condition, accurate contour locations in the SAR image are obtained by applying an active contour model. They found that this snake method outperformed manual registration in terms of root mean square error at the control points. Dare \& Dowman (1996) tried to develop an automatic system for registering SAR data to optical data by feature matching. In order to enhance the extraction of features from SAR images, they tested various speckle reduction filters and segmentation procedures to aid this procedure. Thepaut et al. (1998) proposed an automatic registration method of 
multidate and multisensory, i.e. ERS SAR and SPOT, images based on a multichannel consensual segmentation scheme. Zamora et al. (1998) also used the segmentation technique to register multi-sensor images by adaptive clustering prior to performing preprocessing and cepstrum operation to determine the translational displacement. Raucoules \& Carnec (1999) proposed the use of local correlation to deal with the co-registration of ERS SAR and SPOT orthoimage by taking the interferometric phases as additional information. Dare \& Dowman (2001) introduced an improved model, which is based on their previous work (1996), for automatic feature-based image registration, and presents a robust system for automatically registering SAR and SPOT imagery by incorporating multiple feature extraction and feature matching algorithms. Their experiments on both small and large images showed that in each case a large number of accurate tie points could be identified fully automatically across the images. Ali \& Clausi (2002) conducted an investigation on the development of a fully automatic registration system for SAR and optical remote sensing images. The registration method is based on the extraction and matching of common features that are visible in both images. The algorithm involves the five steps, i.e. noise removal, edge extraction, edge linking pattern extraction and pattern matching. The experiments showed that accurate ground control points (GCPs) could be identified automatically. Hong \& Schowengerdt $(2003 ; 2005)$ proposed an automated precise registration approach of ERS2 SAR and Landsat5 TM images using visually-located control points based pre-registration and large-scale edge gradient contours based preciseregistrtion. Lampropoulos et al. (2003) presents a proof of concept demonstration to perform image registration from dissimilar sources based on multiple transformations of two quite dissimilar images into new domains, where local or global similarities are extracted. Wang \& Chen (2003) proposed an automatic SAR and optical image registration approach based on fuzzy linear feature extraction and neural network controlled resampling and image transformation. Cheng et al. (2004) proposed a SVM (support vector machine) supported edge feature extraction technique to register SAR and optical images. They used a modified Hausdorff distance as a similarity measure and genetic algorithm as the search strategy. Galland et al. (2005) first presented a SAR-to-optical image registration method by using a perfect knowledge of the sensor parameters. They suggested that the feature extraction can be used to perform the refinement of parameters, and the registration can be approximated by simple polynomial transformations. Inglada \& Vadon (2005) proposed a fully automatic approach for the fine registration of SPOT5 and ENVISAT/ASAR IMS data. Shu et al. (2005) implemented a mutual information based registration method to match SAR and SPOT images. They used Gabor filters to extract orientation at four directions to enhance the registration process. The experimental results showed that the approach is much better than coarse manual registration. Yang et al. (2005) presents a SAR-to-optical image registration method by using extracted multiple features to improve the control points. Mao et al. (2007) used the approach being similar with Cheng et al. (2004) to register SAR and optical images based on linear features using Hausdorff distance and genetic algorithm. Shu and Tan (2007) proposed a mutual-information based method to register SAR and SPOT images. The novelty is to calculate local contrast of $5 \times 5$ windows centred at each point in both images, and to obtain two contrast images to be used to accurately register by assigning the contrast values to each pixel. Zhang et al. (2007) proposed a region-feature based automatic registration workflow for ENVISAT/ASAR and Landsat TM images. Wegner and Soergel (2008) proposed a semi-automatic registration approach based on line features for the 
improvement of the bridge scene of interest. They used a road extraction approach based on measuring spectral angels in the optical image, and thresholding and morphological operators for bridge extraction in the SAR image. The distance maps are calculated to transform discrete line segments to continuous two-dimensional information, and such distance maps are finally registered using a global transformation and a cross-correlation metric.

Summarizing the past research, we can find most studies used the feature based registration method (e.g., Wang \& Chen, 2003; Wu \& Maitre, 1990). The key problem of such kind of methods is how to enhance the extraction process of the corresponding features. The registration workflow is usually complicated, and it depends on many assistant means to lubricate the whole process. However, few researchers have tried to automate the SAR-tooptical image registration by using the intensity based approach (e.g., Mao et al., 2007; Shu et al., 2005). This kind of registration methods does not need many assistant means, and fully utilize the intensity information contained in images. The whole registration workflow is driven by an optimization process for similarity measure based object function. This search procedure for the transformation parameters usually needs large amount of computation. In this chapter, we put forth a novel intensity based method to register PALSAR (Kimura \& Ito, 2000) and ASTER images based on our previous work (Li et al., 2007c). The intensity based mutual information is used as the similarity measure to automate the registration process. The multiscale steerable Simoncelli filter (Simoncelli \& Adelson, 1990; Simoncelli \& Farid, 1996; Simoncelli \& Freeman, 1995; Simoncelli et al., 1992) is implemented to lubricate the registration process. A hybrid search technique is used to enhance the optimization process of transformation parameters. The experimental results showed that the proposed registration scheme is competent and feasible for PALSAR and ASTER images.

The whole chapter consists of five sections. The first section shortly reviews the research background of radar and optical image registration, and the latest registration techniques, and our novel registration methodology. The second section addresses a generalized mathematical model with mutual-information based similarity measure and multiscale steerable Simoncelli filter technique. The third section gives the description of PALSAR and ASTER satellite imagery. The fourth section discusses the experiment design, process, and results. The fifth section lays out the concluding remarks.

\section{Algorithm}

\subsection{Image registration}

The task of image registration is fundamental in image processing. Therefore, it is common problems in nearly all the scientific fields associated with image applications (Brown, 1992; Goshtasby, 2005; Maintz \& Viergever, 1998; Pluim et al., 2003; Zitova \& Flusser, 2003). In the literature, image registration is also termed image alignment or image matching (e.g., Chen et al., 2007; Chen et al., 2003; Szeliaki, 2005). From a mathematical point of view, image registration can be defined as a process to search a transformation which determines a mapping that is the best match of two or more images of the same object field, acquired by different sensors, or taken by the same sensor at different times $(\mathrm{Li}, 2006)$. 
For an image pair $\left(I_{F}, I_{R}\right)$ to be registered, the definition of registering the float image $\left(I_{F}\right)$ to the reference image $\left(I_{R}\right)$ can be expressed mathematically as (1):

$$
I_{R}(x, y)=\zeta\left(I_{F}\left(T_{\alpha}(x, y)\right)\right)
$$

where $T_{\alpha}$ is a transformation function, which maps two spatial coordinates $x$ and $y$, to the new spatial coordinates $x^{\prime}$ and $y^{\prime}$ by the set of parameters $\alpha$ as (2):

$$
\left(x^{\prime}, y^{\prime}\right)=T_{\alpha}(x, y)
$$

$\zeta$ is a one dimensional intensity or radiometric interpolation function.

The intensity based image registration can be analyzed as a non-convex optimization problem (Li, 2006; Modersitzki, 2004). This can be expressed mathematically as (3):

$$
\alpha^{*}=\underset{T_{\alpha}}{\operatorname{Arg} \operatorname{optima}}\left(S_{T_{\alpha}}\left(I_{F}, I_{R}\right)\right)
$$

where $S$ is the similarity measure, and $\alpha^{*}$ is the optima estimated by the search algorithm. The generalized registration process using eqns. (1-3) for the intensity based method can always be depicted in Figure 1 (Li et al., 2006c; Yoo, 2004). It can be found that the intensity based image registration is an iterated process to search for the optimized transformation parameters.

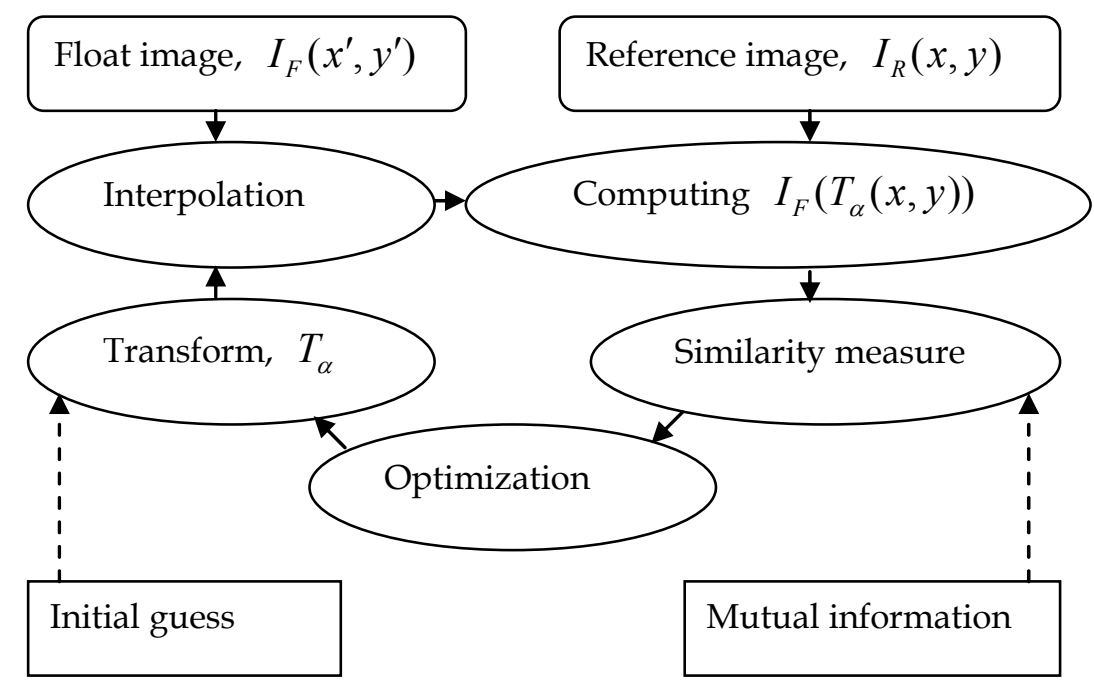

Fig. 1. A generalized framework for intensity based image registration 


\subsection{Mutual information}

As pointed in Figure 1, similarity measure is an element of the image registration. It is used to construct an object function associated with image intensities for the optimization step. It should be noted that the term of similarity measure is different from the term of similarity metric (Cover \& Thomas, 2006). In this chapter, we used the former. Starting in 1995, with the successful implementation of mutual information as a novel similarity measure to the multimodality medical image registration (Maes et al., 1997; Viola \& Wells, 1995), the achievement of the intensity based automated image registration becomes possible. Based on the information theory (Cover \& Thomas, 2006), the standard definition of mutual information, $\operatorname{MI}\left(I_{F}, I_{R}\right)$, of two images $I_{F}$ and $I_{R}$ can be written as (4):

$$
M I\left(I_{F}, I_{R}\right)=H\left(I_{F}\right)+H\left(I_{R}\right)-H\left(I_{F}, I_{R}\right)
$$

where $H\left(I_{F}\right)$ and $H\left(I_{R}\right)$ are the marginal entropies of $I_{F}$ and $I_{R}$, and $H\left(I_{F}, I_{R}\right)$ is their joint entropy. Considering the definition in (4), the mutual information is maximal when the two images are totally geometrically aligned by a certain transformation matrix. In practice, the normalized version (NMI) of the standard mutual information is popular. It may be defined as (5):

$$
\operatorname{NMI}\left(I_{F}, I_{R}\right)=\frac{H\left(I_{F}, I_{R}\right)}{H\left(I_{F}\right)+H\left(I_{R}\right)}
$$

In order to compute of mutual information, the marginal entropies and joint entropy of the image pair should be calculated. These entropies can be calculated from the probability density functions. Furthermore, these probability density functions can be estimated from the histogram of images or other tricks such as Parzen windows (Glavinovic, 1996; Parzen, 1962). The detailed computation is left out in this chapter and it can be found in (Maes et al., 1997; Viola \& Wells, 1995).

\subsection{Simoncelli filter}

The multiresolution decomposition techniques using wavelet-like filters are usually adopted to enhance the image registration (Le Moigne et al., 2002). Because the steerable Simoncelli filters are more robust to translation, rotation and noise than the standard Daubechies wavelet filters (Cole-Rhodes et al., 2003), it enables us to use it for registration of SAR and optical satellite images (Li et al., 2007c).

According to the definition of steerable Simoncelli filters (Simoncelli \& Freeman, 1995), the steerable pyramid is a multiscale representation that is translation-invariant, but that also includes representation of orientation. Furthermore, the representation of orientation is designed to be rotation-invariant. The basis and projection functions are oriented (i.e., steerable) filters, localized in space and frequency. It is overcomplete to avoid aliasing. It is also "tight frame", i.e. the projection functions and basis functions are identical, though it is not an orthogonal representation. 
The diagram for steerable Simoncelli pyramid may be depicted in Figure 2. The filters \{Fhi0, Flo0\} are used to initially split the image into a highpass residual band and a lowpass subband. This lowpass band Flo0 is then split into some lowerpass bands \{Flo1, Flo2, ...\}. $\{\mathrm{FB} 0, \mathrm{FB} 1, \ldots\}$ represent the oriented subbands which ensure that the representation is rotation-invariant. In order to ensure some translation-invariance, the outputs of the highpass filter and of the band-pass filters are not subsampled. The resulting transform is overcomplete by a factor of $4 \mathrm{k} / 3$, where $\mathrm{k}$ is the number of oriented band-pass filters. The scale tuning of the filters is constrained by the recursive system diagram. The orientation tuning is constrained by requiring the property of steerability (Cole-Rhodes et al., 2003; Li et al., 2007c; Simoncelli \& Freeman, 1995).

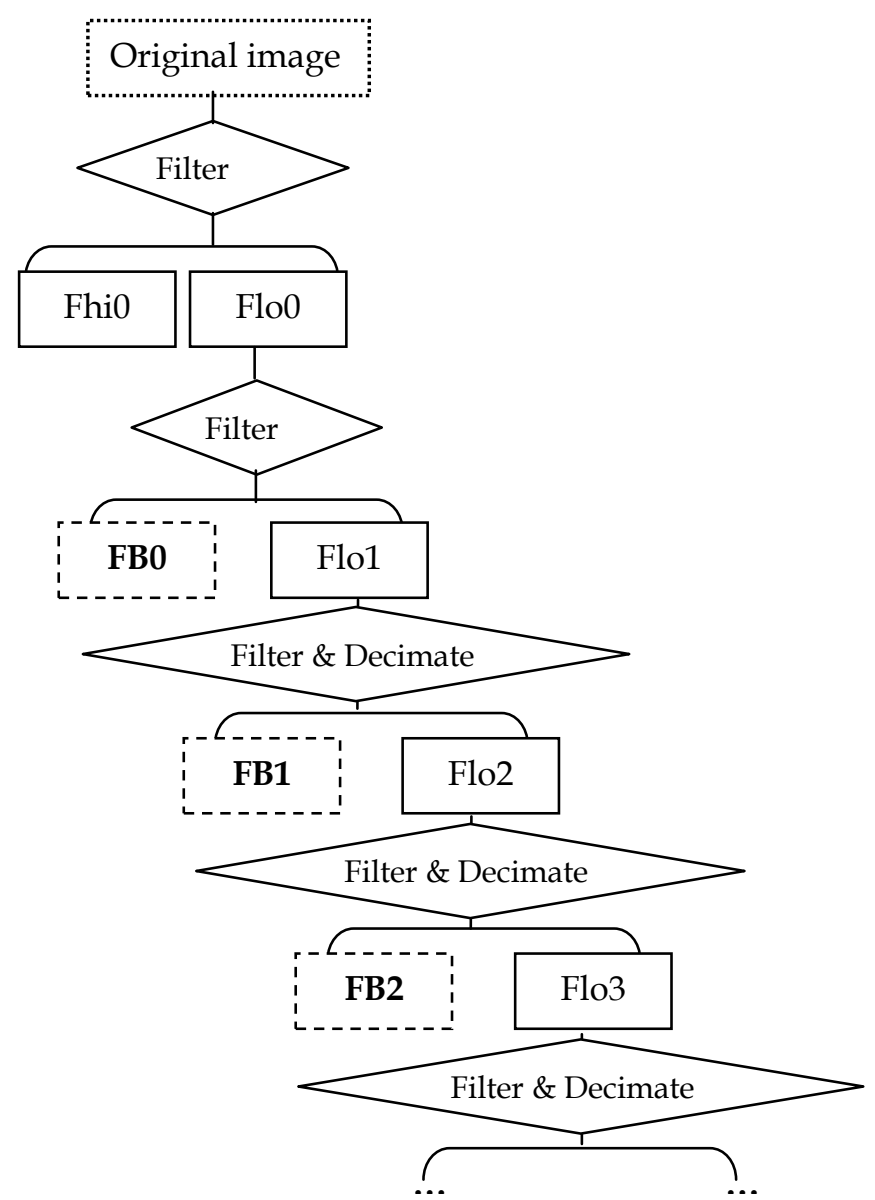

Fig. 2. A steerable Simoncelli pyramid with three-level decompositions of original image 


\subsection{Workflow}

As shown in Figure 1, the computational process of intensity based image registrations can be partitioned into four major modules, i.e., intensity interpolation, mapping transformation, similarity measure, and optimization strategy for the parameter space. Till now, our developed registration system has implemented 7 interpolation algorithms, 25 similarity measures, 11 optimization algorithms, and it supported 7 transformations from rigid to polynomial mapping ( $\mathrm{Li}$ et al., 2007a). The whole workflow of image registration in this chapter can be depicted in Figure 3.

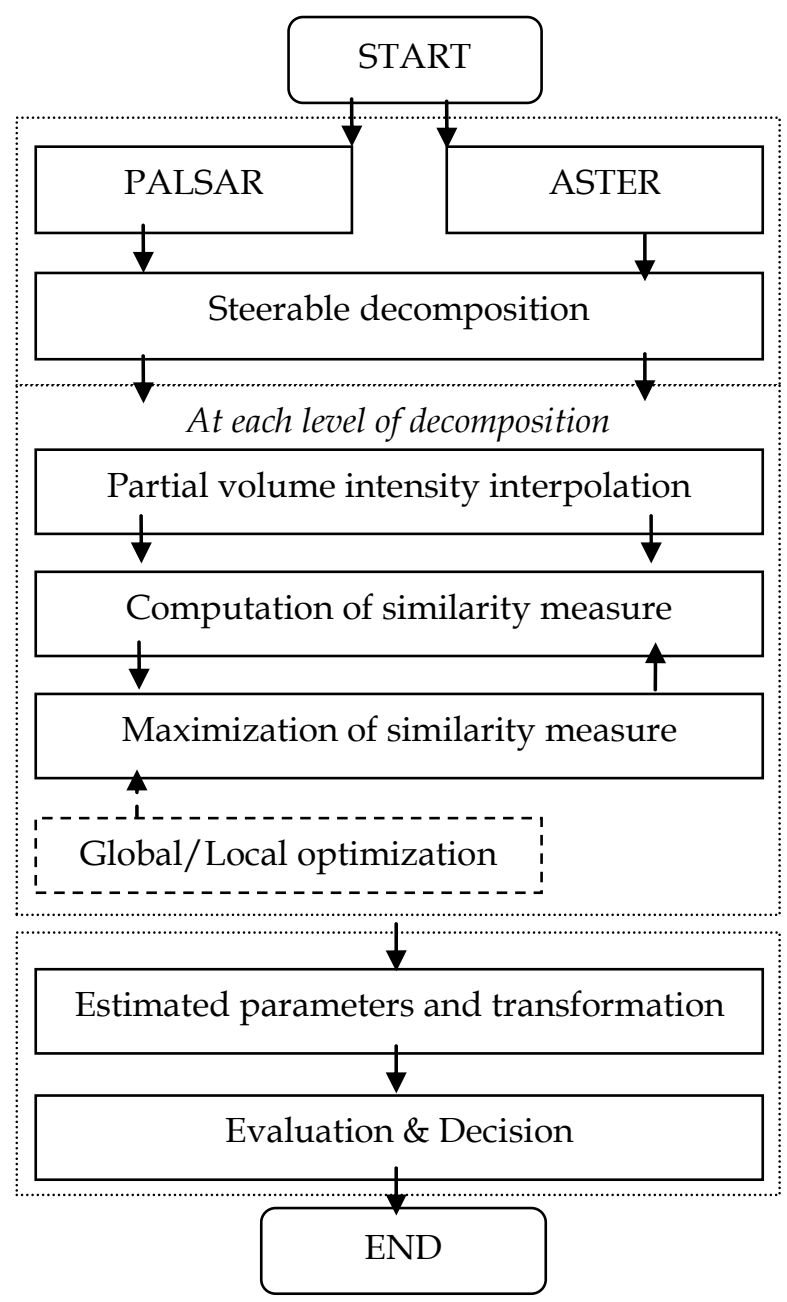

Fig. 3. Workflow of SAR-to-optical image registration 


\section{Data}

\subsection{ASTER}

The Advanced Spaceborne Thermal Emission and Reflection Radiometer (ASTER) sensor instrument was launched in December 18, 1999, onboard the first NASA's EOS series of satellites, Terra. ASTER covers a wide spectral region with 14 bands from visible to thermal infrared with high spatial, spectral and radiometric resolution. Three visible and near infrared (VNIR) bands, six shortwave infrared (SWIR) bands, and five thermal infrared (TIR) bands have a spatial resolution of $15 \mathrm{~m}, 30 \mathrm{~m}$, and $90 \mathrm{~m}$, respectively. In addition, ASTER has a stereoscopic capability for the bands (bands $3 \mathrm{~N}$ and $3 \mathrm{~B}$ ) in near infrared region (Iwasaki \& Fujisada, 2005; Yamaguchi et al., 1998), and so far, it can generate Digital Elevation Model (DEM) data with high accuracy (Fujisada et al., 2005).

ASTER-TIR is the first satellite-borne multispectral TIR remote sensing system with spectral, spatial and radiometric resolutions adequate for geological applications (e.g., Ninomiya et al., 2005). Compared with two bands of Landsat TM or ETM in SWIR region (between 1.6 to 2.5 microns), ASTER sensor has 6 bands in this region and provides an opportunity to identify mineral component of surface rocks in the semi-arid to arid region (e.g., Rowan \& Mars, 2003). Therefore, ASTER imaging system can provide some important capabilities to identify lithologic and mineralogic features on earth surface (e.g., Fu et al., 2007; Ninomiya et al., 2005). Especially, ASTER multispectral TIR sensor can provide an important tool for monitoring heat flow related to volcanic activities (e.g., Urai et al., 2007). Therefore, ASTER can provide a potential tool for mapping the wide multiple-aim geologic products from regional to global scales because high-resolution multispectral dada obtained by ASTER can cover almost throughout earth surface.

\subsection{PALSAR}

PALSAR is the abbreviation of Phased Array type L-band Synthetic Aperture Radar. It is an active microwave sensor using L-band frequency, operated at all-weather conditions regardless of day and night, launched with ALOS satellite on January 24, 2006 in Japan. It is improved based on SAR onboard the first earth observation satellite (JERS-1) with multimode observation functions of multi-polarization, variable off-nadir angle, and switching spatial resolution and swath width observation (Igarashi, 2000; Kimura \& Ito, 2000). It provides higher performance than the JERS-1's SAR with a totally new advantageous observation mode (i.e., ScanSAR). PALSAR has incorporated many highly advanced observation technologies, and is expected to contribute greatly in areas such as resource exploration, environmental monitoring on earth and monitoring of natural disasters (e.g., Rosenqvist et al., 2007; Takada et al., 2009). The signals are recorded in complex notation on PALSAR sensor from which their amplitude and phases could be computed. The specifications of PALSAR sensor can be summarized in Table 1. It should be noted that PALSAR sensor can not observe the areas beyond 87.8 Degrees north latitude and 75.9 Degrees south latitude, when the off-nadir angle is 41.5 Degrees (http://www.eorc.jaxa.jp/ALOS/en/about/palsar.htm).

\subsection{Image set}

In this chapter, all image pairs were extracted from each of the full scene ASTER and PALSAR data. The ASTER L1B Band 1 data and PALSAR fine mode data were used in the 
experiments. The extracted sub-images for experiments have $128 \times 128,256 \times 256,512 \times 512$, $1024 \times 1024$ pixels, respectively. The research area covers the part of the city of Tokyo, Japan. One sub-image pair has been shown in Figure 4. The very clear difference in terms of visual appearance of features can be observed. The same spatial features can not be easily found from both images. PALSAR image is inevitably contaminated by the speckle noise and strongly scattered signals from any corners on the earth surface. In principle, physical properties and viewing geometries between ASTER and PALSAR images are intrinsic different. However, the effect resulted from the viewing geometry will be alleviated in flat regions.

\begin{tabular}{|c|c|c|c|c|}
\hline Mode & \multicolumn{2}{|l|}{ Fine } & ScanSAR & Polarimetric* \\
\hline Center frequency (MHz) & \multicolumn{4}{|c|}{1270 (L-band) } \\
\hline Chirp bandwidth (MHz) & 28 & 14 & 14,28 & 14 \\
\hline Polarization & $\begin{array}{l}\mathrm{HH} \\
\mathrm{VV}\end{array}$ & $\begin{array}{l}\mathrm{HH}+\mathrm{HV} \\
\mathrm{VV}+\mathrm{VH}\end{array}$ & $\begin{array}{l}\mathrm{HH} \\
\mathrm{VV}\end{array}$ & $\mathrm{HH}+\mathrm{HV}+\mathrm{VH}+\mathrm{VV}$ \\
\hline Incident angle (Degree) & $8-60$ & $8-60$ & $18-43$ & $8-30$ \\
\hline Range resolution (m) & $7-44$ & $14-88$ & 100 (Multi look) & $24-89$ \\
\hline Observation swath (km) & $40-70$ & $40-70$ & $250-350$ & $20-65$ \\
\hline Bit length (bits) & 5 & 5 & 5 & 3 or 5 \\
\hline Data rate (Mbps) & 240 & 240 & 120,240 & 240 \\
\hline NE sigma zero ** $(\mathrm{dB})$ & \multicolumn{2}{|c|}{$\begin{array}{l}<-23 \text { (Swath width } 70 \mathrm{~km}) \\
<-25 \text { (Swath width } 60 \mathrm{~km})\end{array}$} & $<-25$ & $<-29$ \\
\hline $\mathrm{S} / \mathrm{A}^{* * *}(\mathrm{~dB})$ & \multicolumn{2}{|c|}{$\begin{array}{l}>16 \text { (Swath width } 70 \mathrm{~km}) \\
>21 \text { (Swath width } 60 \mathrm{~km})\end{array}$} & $>21$ & $>19$ \\
\hline Radiometric accuracy & \multicolumn{4}{|c|}{ Scene: $1 \mathrm{~dB} /$ Orbit: $1.5 \mathrm{~dB}$} \\
\hline
\end{tabular}

* Due to power consumption, the operation time will be limited.

** Valid for off-nadir angle with 34.3 Degrees (Fine mode), 34.1 Degrees (ScanSAR mode), 21.5 Degrees (Polarimetric mode).

*** S/A level may deteriorate due to engineering changes in PALSAR

Table 1. Characteristics of PALSAR 

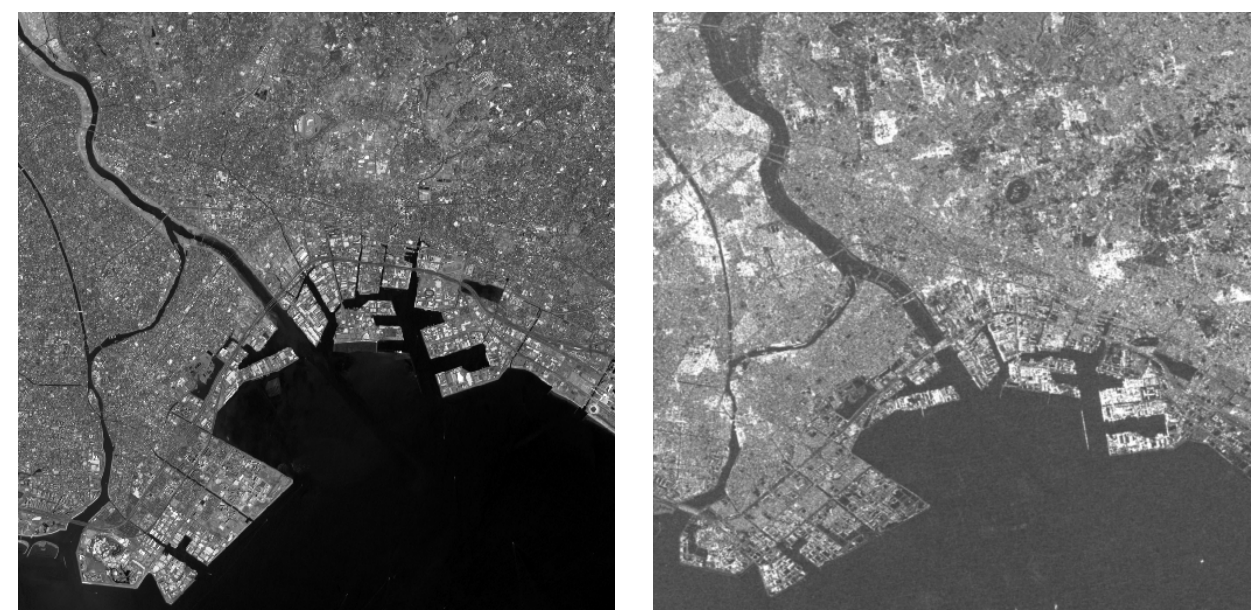

Fig. 4. ASTER (left) and PALSAR (right) images of Tokyo bay, Japan with 512x512 pixels

\section{Experiments}

The registration scheme of our proposed method (Figure 3) includes three major stages similar with our previous work ( $\mathrm{Li}$ et al., 2007c). Both SAR and optical image are firstly decomposed into a steerable pyramid. Subbands FBi (Figure 2) are utilized to extract features in the provided image set. The partial volume intensity interpolation ( $\mathrm{Li}$ et al., 2006a) is adopted for the estimation of probability density functions. The particle swarm optimization (Li \& Sato, 2007) is used to globally search the parameter space of the registration function at the coarsest level. The local stochastic gradient search, which is conducted by a simultaneous perturbation stochastic approximation technique (Li et al., 2006b; 2007b), is implemented to optimize the registration function at other levels. The result of the global optimization is used as the initial guess of the local stochastic gradient search.

Figure 5 shows the visualization check of one registration result. By visual comparison, we can note that the registration of the proposed scheme is much better than the manual method conducted in some commercial software. To do a numerical comparison, we manually locate 5-10 pairs of check points with a good distribution and evaluate the registration accuracies according to RMSE (root mean squared error). The RMSE values are 5-7 pixels for manual registration and 1-3 pixels for our registration. This indicates that the registration accuracy is greatly improved by our proposed scheme. In particular, the results are better than our previous work on the registration of JERS-1 SAR and ASTER images (Li et al., 2007c). 

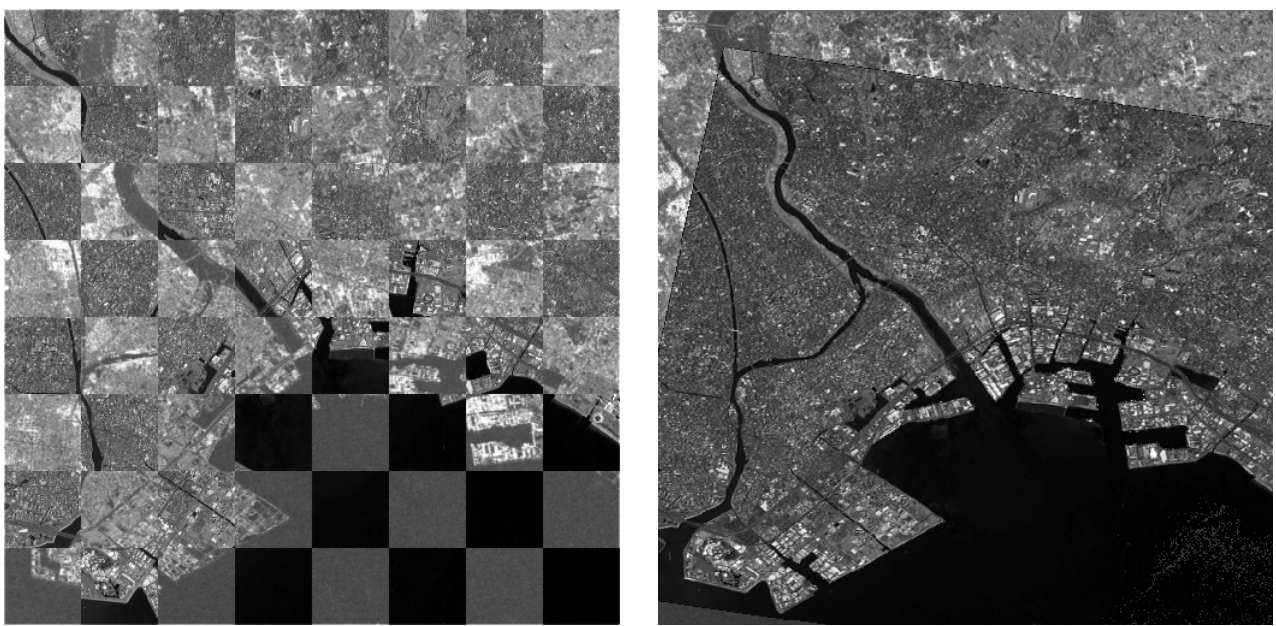

Fig. 5. Visualizing check of PALSAR and ASTER image (Left: before registration; Right: after affine registration)

\section{Conclusions}

The experimental results showed that proposed scheme can be capable to register radar and optical satellite images such as PALSAR and ASTER images. Compared to the traditional manual method, the scheme using multiscale filter technique and information measure can greatly enhance the registration process. The hybrid search/optimization approach is relatively less sensitive to initial guess, and make the registration process robust. Meanwhile, our method maintains comparable accuracy comparing with the traditional manual method. Except for the computing time, the scheme might encounter difficulties when the two images with very time differences.

Future work should include two parts. The first one is to conduct many more experiments on different regions. The other one is to incorporate some feature based technique to speed up the search process.

\section{Acknowledgements}

This research has been mainly funded under the research contract with the Ministry of Economy, Trade and Industry (METI), Japan as the part of the R\&D of Remote Sensing Technologies for Non-renewable Resources (SEKITOKU). QL would like to thank I. Sato, Y. Murakami, M. Urai, Y. Ninomiya, F. Sakuma, and S. Okuyama (AIST) for all of their help. ASTER and PALSAR data were provided by the Earth Remote Sensing Data Analysis Centre (ERSDAC), Japan. 


\section{References}

Ali, M.A. \& Clausi, D.A. (2002). Automatic registration of SAR and visible band remote sensing images, Proceedings of the 22nd IEEE International Geoscience and Remote Sensing Symposium (IGARSS 2002)/24th Canadian Symposium on Remote Sensing - Remote Sensing: Integrating Our View of The Planet, pp. 1331-1333, 07803-7536-X, Toronto, Canada, June 24-28, 2002, IEEE, New York

Barrett, E.C.; Brown, K.A. \& Micallef, A. (Eds.) (1991). Remote sensing for hazard monitoring and disaster assessment: Marine and coastal applications in the mediterranean region, Gordon and Breach Science Publishers, 2-8812-4809-8, Philadelphia, PA, USA

Brown, L.G. (1992). A survey of image registration techniques. ACM Computing Surveys, Vol.24, No.4, (December 1992) page numbers (325-376), 0360-0300

Chen, F.; Wang, C. \& Zhang, H. (2007). Automatic matching of high-resolution SAR images. International Journal of Remote Sensing, Vol.28, No.16, (January 2007) page numbers (3665-3678), 0143-1161

Chen, G.H.; Tang, L.L.; Dai, C.D. \& Jiang, X.G. (2003). Selection of fusing methods with SAR and TM data to monitor flood quickly, Proceedings of Conference on Image Processing and Pattern Recognition in Remote Sensing, pp. 162-170, 0-8194-4684-X, Hangzhou, China, October 25-27, 2002, SPIE, Bellingham, WA, USA

Chen, H.; Varshney, P.K. \& Arora, M.K. (2003). Mutual information based image registration for remote sensing data. International Journal of Remote Sensing, Vol.24, No.18, (September 2003) page numbers (3701-3706), 0143-1161

Cheng, H.; Zheng, S.; Yu, Q.Z.; Tian, J.W. \& Liu, J. (2004). Matching of SAR images and optical images based on edge feature extracted via SVM, Proceedings of the 7 th International Conference on Signal Processing, pp. 930-933, 7-121-00215-9, Beijing, China, August 31-September 04, 2004, Publishing House Electronics Industry, Beijing

Chevrel, M.; Courtois, M. \& Weill, G. (1981). The SPOT satellite remote-sensing mission. Photogrammetric Engineering and Remote Sensing, Vol.47, No.8, (August 1981) page numbers (1163-1171), 0099-1112

Chuvieco, E. (Ed.) (2008). Earth observation of global change: The role of satellite remote sensing in monitoring the global environment, Springer, 1-4020-6357-1, London, UK

Cole-Rhodes, A.A.; Johnson, K.L.; LeMoigne, J. \& Zavorin, I. (2003). Multiresolution registration of remote sensing imagery by optimization of mutual information using a stochastic gradient. IEEE Transactions on Image Processing, Vol.12, No.12, (December 2003) page numbers (1495-1511), 1057-7149

Cover, T.M. \& Thomas, J.A. (2006). Elements of information theory, Wiley-Interscience, 0471-24195-4, New York

Curlander, J. \& Kober, W. (1990). Innovative algorithms for SAR to optical-image registration, Proceedings of the 10th Annual International Geoscience and Remote Sensing Symposium: Remote Sensing Science for the Nineties, pp. 329-331, College Park, MD, USA, May 20-24, 1990, IEEE, New York

Dare, P.M. \& Dowman, I.J. (1996). Automated procedure for registering SAR and optical imagery based on feature matching, Proceedings of Conference on Microwave Sensing and Synthetic Aperture Radar, pp. 140-151, 0-8194-2362-9, Taormina, Italy, September 23-26, 1996, SPIE, Bellingham, WA, USA 
Dare, P.M. \& Dowman, I.J. (2001). An improved model for automatic feature-based registration of SAR and SPOT images. ISPRS Journal of Photogrammetry and Remote Sensing, Vol.56, No.1, (June 2001) page numbers (13-28), 0924-2716

Franceschetti, G. \& Lanari, R. (1999). Synthetic aperture radar processing, CRC, 0-8493-78990 , Boca Raton, FL, USA

Fu, B.H.; Ninomiya, Y.; Lei, X.L.; Toda, S. \& Awata, Y. (2004). Mapping active fault associated with the $2003 \mathrm{Mw}$ 6.6 Bam (SE Iran) earthquake with ASTER 3D images. Remote Sensing of Environment, Vol.92, No.2, (August 2004) page numbers (153157), 0034-4257

Fu, B.H.; Shi, P.L.; Wang, P.; Li, Q.; Kong, P. \& Zheng, G.D. (2009). Geometry and kinematics of the 2008 Wenchuan earthquake surface ruptures around the Qushan town of Beichuan county, Sichuan: Implications for mitigation of seismic and geologic disasters. Chinese Journal of Geophysics-Chinese Edition, Vol.52, No.2, (February 2009) page numbers (485-495), 0001-5733

Fu, B.H.; Zheng, G.D.; Ninomiya, Y.; Wang, C.Y. \& Sun, G.Q. (2007). Mapping hydrocarboninduced mineralogical alteration in the northern Tian Shan using ASTER multispectral data. Terra Nova, Vol.19, No.4, (August 2007) page numbers (225231), 0954-4879

Fujisada, H.; Bailey, G.B.; Kelly, G.G.; Hara, S. \& Abrams, M.J. (2005). ASTER DEM performance. IEEE Transactions on Geoscience and Remote Sensing, Vol.43, No.12, (December 2005) page numbers (2707-2714), 0196-2892

Galland, F.; Tupin, F.; Nicolas, J.-M. \& Roux, M. (2005). Registering of synthetic aperture radar and optical data, Proceedings of the 25th IEEE International Geoscience and Remote Sensing Symposium (IGARSS 2005), pp. 3513-3516, 0-7803-9050-4, Seoul, South Korea, July 25-29, 2005, IEEE, New York

Glavinovic, M.I. (1996). Comparison of parzen density and frequency histogram as estimators of probability density functions. Pflugers Archiv-European Journal of Physiology, Vol.433, No.1-2, (November-December 1996) page numbers (174-179), 0031-6768

Goshtasby, A.A. (2005). 2-D and 3-D image registration: For medical, remote sensing, and industrial applications, Wiley-Interscience, 0-4716-4954-6, New York

Hong, T.D. \& Schowengerdt, R.A. (2003). Automated precise registration of radar and optical satellite images, Proceedings of Conference on Applications of Digital Image Processing XXVI, pp. 88-96, 0-8194-5076-6, San Diego, CA, USA, August 0508, 2003, SPIE, Bellingham, WA, USA

Hong, T.D. \& Schowengerdt, R.A. (2005). A robust technique for precise registration of radar and optical satellite images. Photogrammetric Engineering and Remote Sensing, Vol.71, No.5, (May 2005) page numbers (585-594), 0099-1112

Igarashi, T. (2000). ALOS mission requirement and sensor specifications. Advances in Space Research, Vol.28, No.1, (2001) page numbers (127-131), 0273-1177

Inglada, J. \& Giros, A. (2004). On the possibility of automatic multisensor image registration. IEEE Transactions on Geoscience and Remote Sensing, Vol.42, No.10, (October 2004) page numbers (2104-2120), 0196-2892

Inglada, J. \& Vadon, H. (2005). Fine registration of SPOT5 and Envisat/ASAR images and ortho-image production: A fully automatic approach, Proceedings of the 25th IEEE International Geoscience and Remote Sensing Symposium (IGARSS 2005), pp. $3510-$ 3512, 0-7803-9050-4, Seoul, South Korea, July 25-29, 2005, IEEE, New York 
Iwasaki, A. \& Fujisada, H. (2005). ASTER geometric performance. IEEE Transactions on Geoscience and Remote Sensing, Vol.43, No.12, (December 2005) page numbers (2700-2706), 0196-2892

Kafatos, M. \& Qu, J.J. (2007). Introduction to science and instruments, In: Earth science satellite remote sensing: Science and instruments, Qu, J.J.; Gao, W.; Kafatos, M.; Murphy, R.E. \& Salomonson, V.V., (Eds.), page numbers (1-11), Tsinghua University Press and Springer, 7-302-12844-8, Beijing and Berlin

Kaufman, Y.J.; Herring, D.D.; Ranson, K.J. \& Collatz, G.J. (1998). Earth observing system AM1 mission to earth. IEEE Transactions on Geoscience and Remote Sensing, Vol.36, No.4, (July 1998) page numbers (1045-1055), 0196-2892

Kimura, H. \& Ito, N. (2000). ALOS/PALSAR: The Japanese second-generation spaceborne SAR and its applications, Proceedings of Conference on Microwave Remote Sensing of the Atmosphere and Environment II, pp. 110-119, 0-8194-3805-7, Sendai, Japan, October 09-12, 2000, SPIE, Bellingham, WA, USA

Lampropoulos, G.A. \& Boulter, J.F. (1997). A new nonlinear speckle and noise reduction algorithm, Proceedings of 5th Conference on Infrared Spaceborne Remote Sensing, pp. 260-270, 0-8194-2544-3, San Diego, CA, USA, July 30-August 01, 1997, SPIE, Bellingham, WA, USA

Lampropoulos, G.A.; Chan, J.; Secker, J.; Li, Y. \& Jouan, A. (2003). Automatic registration of electro-optical and SAR images, Proceedings of IEEE Workshop on Advances in Techniques for Analysis of Remotely Sensed Data held in Honor of David A Landgrebe, pp. 219-226, 0-7803-8350-8, Greenbelt, MD, USA, October 27-28, 2003, IEEE, New York

Lampropoulos, G.A.; Li, Y.F.; Secker, J.; Sevigny, L. \& Beaudoin, A. (2002). Electro-optical and SAR image fusion for improvements on target feature estimation, Proceedings of the 5th International Conference on Applications of Photonic Technology (ICAPT 2002), pp. 214-225, 0-8194-4612-2, Quebec City, Canada, June 01-06, 2002, SPIE, Bellingham, WA, USA

Le Moigne, J.; Cole-Rhodes, A.; Eastman, R.; El-Ghazawi, T.; Johnson, K.; Kaewpijit, S.; Laporte, N.; Morisette, J.; Netanyahu, N.S.; Stone, H.S. \& Zavorin, I. (2002). Multiple sensor image registration, image fusion and dimension reduction of earth science imagery, Proceedings of the 5th International Conference on Information Fusion (FUSION 2002), pp. 999-1006, 0-9721844-2-2, Annapolis, MD, USA, July 0811, 2002, International Society of Information Fusion (ISIF), Sunnyvale, CA, USA

Li, H.; Manjunath, B.S. \& Mitra, S.K. (1993). Optical-to-SAR image registration using the active contour model, Proceedings of the 27th Asilomar Conference on Signals, Systems and Computers, pp. 568-572, 0-8186-4120-7, Pacific Grove, CA, USA, November 01-03, 1993, IEEE, Computer Society Press, Los Alamitos, CA, USA

Li, H.; Manjunath, B.S. \& Mitra, S.K. (1995). A contour-based approach to multisensor image registration. IEEE Transactions on Image Processing, Vol.4, No.3, (March 1995) page numbers (320-334), 1057-7149

$\mathrm{Li}, \mathrm{Q}$. (2006). Challenging registration of geologic image data - initialization, estimation, and decision. Seminar Note of Mathematical Sciences, Vol.10, (September 8-10, 2006) page numbers (78-87), ISSN-N/A 
Li, Q.; Ito, K.; Tomishima, Y. \& Seki, Y. (2009). Bridging satellite monitoring and characterization of subsurface flow: With a case of Horonobe Underground Research Laboratory, In: Prediction and simulation methods for geohazard mitigation, Oka, F.; Murakami, A. \& Kimoto, S., (Eds.), page numbers (519-524), CRC Press, 978-0-415-80482-0, New York

Li, Q. \& Sato, I. (2007). Multimodality image registration by particle swarm optimization of mutual information. Lecture Notes in Artificial Intelligence, Vol.4682, (August 2007) page numbers (1120-1130), 0302-9743

Li, Q.; Sato, I. \& Murakami, Y. (2006a). Interpolation effects on accuracy of mutual information based image registration, Proceedings of 2006 IEEE International Geoscience and Remote Sensing Symposium / 27th Canadian Symposium on Remote Sensing Remote Sensing: A Natural Global Partnership (IGARSS 2006), pp. 180-183, 0-78039510-7, Denver, Colorado, USA, July 31 - August 4, 2006, IEEE, New York

Li, Q.; Sato, I. \& Murakami, Y. (2006b). Simultaneous perturbation stochastic approximation algorithm for automated image registration optimization, Proceedings of 2006 IEEE International Geoscience and Remote Sensing Symposium / 27th Canadian Symposium on Remote Sensing - Remote Sensing: A Natural Global Partnership (IGARSS 2006), pp. 184-187, 0-7803-9510-7, Denver, CO, USA, 31 July - 4 August, 2006, IEEE, New York

Li, Q.; Sato, I. \& Murakami, Y. (2006c). Toward the establishment of robust automatic system for multimodal image registration, Proceedings of The 40th (2006 Spring) Annual Meeting of the Remote Sensing Society of Japan, pp. 101-102, Keyaki Kaikan, Chiba University, Chiba, Japan, May 18-19, 2006, The Remote Sensing Society of Japan (RSSJ), Tokyo

Li, Q.; Sato, I. \& Murakami, Y. (2007a). Current status of automatic image registration system GSJ/AIR for geologic image integration analysis, Proceedings of The 42nd (2007 Spring) Annual Meeting of the Remote Sensing Society of Japan, pp. 221-222, College of Humanities and Sciences, Nihon University, May 10-11, 2007, The Remote Sensing Society of Japan (RSSJ), Tokyo

Li, Q.; Sato, I. \& Murakami, Y. (2007b). Efficient stochastic gradient search for automatic image registration. International Journal of Simulation Modelling, Vol.6, No.2, page numbers (114-123), 1726-4529

Li, Q.; Sato, I. \& Murakami, Y. (2007c). Steerable filter based multiscale registration method for JERS-1 SAR and ASTER images, Proceedings of 2007 IEEE International Geoscience and Remote Sensing Symposium (IGARSS 2007). Sensing and Understanding Our Planet, pp. 381-384, 978-1-4244-1212-9, Barcelona, Spain, 23-28 July 2007, IEEE, New York

Li, Q.; Sato, I. \& Sakuma, F. (2008). A novel strategy for precise geometric registration of GIS and satellite images, Proceedings of 2008 IEEE International Geoscience and Remote Sensing Symposium - Geoscience and Remote Sensing: The Next Generation (IGARSS 2008), pp. II-1092-II-1095, 978-1-4244-2807-6, Boston, MA, USA, July 6-11, 2008, IEEE, New York

Maes, F.; Collignon, A.; Vandermeulen, D.; Marchal, G. \& Suetens, P. (1997). Multimodality image registration by maximization of mutual information. IEEE Transactions on Medical Imaging, Vol.16, No.2, (April 1997) page numbers (187-198), 0278-0062

Maintz, J.B.A. \& Viergever, M.A. (1998). A survey of medical image registration. Medical Image Analysis, Vol.2, No.1, (March 1998) page numbers (1-36), 1361-8415 
Mao, H.C.; Yu, Q.Z. \& Zhang, T.X. (2007). Matching SAR image to optical image using modified hausdorff distance and genetic algorithms, Proceedings of Conference on Pattern Recognition and Computer Vision, art. No. 678820, 978-0-8194-6952-6, Wuhan, China, November 15-17, 2007, SPIE, Bellingham, WA, USA

Modersitzki, J. (2004). Numerical methods for image registration, Oxford University Press, 0-1985-2841-8, New York

Ninomiya, Y.; Fu, B.H. \& Cudahy, T.J. (2005). Detecting lithology with advanced spaceborne thermal emission and reflection radiometer (ASTER) multispectral thermal infrared "Radiance-at-sensor" Data. Remote Sensing of Environment, Vol.99, No.1-2, (November 2005) page numbers (127-139), 0034-4257

Ninomiya, Y.; Fu, B.H. \& Cudahy, T.J. (2006). Detecting lithology with advanced spaceborne thermal emission and reflection radiometer (ASTER) multispectral thermal infrared "Radiance-at-sensor" Data" (vol 99, pg 127, 2005). Remote Sensing of Environment, Vol.101, No.4, (April 2006) page number (567), 0034-4257

Parzen, E. (1962). On estimation of a probability density function and mode. Annals of Mathematical Statistics, Vol.33, No.3, page numbers (1065-1076), 0003-4851

Pluim, J.P.W.; Maintz, J.B.A. \& Viergever, M.A. (2003). Mutual-information-based registration of medical images: A survey. IEEE Transactions on Medical Imaging, Vol.22, No.8, (August 2003) page numbers (986-1004), 0278-0062

Raucoules, D. \& Carnec, C. (2000). Use of interferometric phase for co-registration of ERS SAR and SPOT images, Proceedings of CEOS SAR Workshop, pp. 113-117, 92-9092641-4, Toulouse, France, October 26-29, 1999, European Space Agency, Paris, France

Realmuto, V.J. (2000). The potential use of earth observing system data to monitor the passive emission of sulfur dioxide from volcanoes, In: Remote sensing of active volcanism, Mouginis-Mark, P.J.; Crisp, J.A. \& Fink, J.H., (Eds.), page numbers (101115), AGU, 0-87590-099-2, Washington DC, USA

Rosenqvist, A.; Shimada, M.; Ito, N. \& Watanabe, M. (2007). ALOS PALSAR: A pathfinder mission for global-scale monitoring of the environment. IEEE Transactions on Geoscience and Remote Sensing, Vol.45, No.11, (November 2007) page numbers (3307-3316), 0196-2892

Rowan, L.C. \& Mars, J.C. (2003). Lithologic mapping in the mountain pass, california area using advanced spaceborne thermal emission and reflection radiometer (ASTER) data. Remote Sensing of Environment, Vol.84, No.3, (March 2003) page numbers (350-366), 0034-4257

Sato, I.; Li, Q.; Nomura, L.; Bandibus, J.; Nishida, K.; Masuda, T. \& Kita, Y. (2006). Research and development of resource fusion technology (part of advanced research of utilization technology of satellite images), In: Report on R\&D of remote sensing technologies for non-renewable resources 1/3, page numbers (1.1.A.1-12), National Institute of Advanced Industrial Science and Technology (AIST), Tsukuba, Japan

Schowengerdt, R.A. (2006). Remote sensing: Models and methods for image processing, Academic Press, 0-1236-9407-8, New York

Shu, L.X. \& Tan, T.N. (2007). SAR and SPOT image registration based on mutual information with contrast measure, Proceedings of 2007 IEEE International Conference on Image Processing (ICIP 2007), pp. 2681-2684, 978-1-4244-1436-9, San Antonio, TX, USA, September 16-19, 2007, IEEE, New York 
Shu, L.X.; Tan, T.N.; Tang, M. \& Pan, C.H. (2005). A novel registration method for SAR and SPOT images, Proceedings of 2005 IEEE International Conference on Image Processing (ICIP 2005), pp. 213-216, 0-7803-9134-9, Genova, Italy, September 11-14, 2005, IEEE, New York

Simoncelli, E.P. \& Adelson, E.H. (1990). Nonseparable extensions of quadrature mirror filters to multiple dimensions. Proceedings of the IEEE, Vol.78, No.4, (April 1990) page numbers (652-664), 0018-9219

Simoncelli, E.P. \& Farid, H. (1996). Steerable wedge filters for local orientation analysis. IEEE Transactions on Image Processing, Vol.5, No.9, (September 1996) page numbers (1377-1382), 1057-7149

Simoncelli, E.P. \& Freeman, W.T. (1995). The steerable pyramid: A flexible architecture for multi-scale derivative computation, Proceedings of International Conference on Image Processing (ICIP 1995), pp. 444-447, 0-7803-3122-2, Washington, DC, USA, October 23-26, 1995, IEEE, New York

Simoncelli, E.P.; Freeman, W.T.; Adelson, E.H. \& Heeger, D.J. (1992). Shiftable multiscale transforms. IEEE Transactions on Information Theory, Vol.38, No.2, (March 1992) page numbers (587-607), 0018-9448

Szeliaki, R. (2005). Image alignment and stitching, In: Handbook of mathematical models in computer vision, Paragios, N.; Chen, Y. \& Faugeras, O., (Eds.), page numbers (273292), Springer, 0-3872-6371-3, New York

Takada, M.; Mishima, Y. \& Natsume, S. (2009). Estimation of surface soil properties in peatland using ALOS/PALSAR. Landscape and Ecological Engineering, Vol.5, No.1, (February 2009) page numbers (45-58), 1860-1871

Tanaka, S. \& Sugimura, T. (2001). A new frontier of remote sensing from IKONOS images. International Journal of Remote Sensing, Vol.22, No.1, (January 2001) page numbers (1-5), 0143-1161

Teeuw, R.M. (Ed.) (2007). Mapping hazardous terrain using remote sensing, Geological Society, 1-8623-9229-3, London, UK

Thepaut, O.; Kpalma, K. \& Ronsin, J. (1998). ERS SAR and SPOT images automatic registration in a multichannel consensual segmentation scheme, Proceedings of 1998 International Geoscience and Remote Sensing Symposium (IGARSS 198) on Sensing and Managing the Environment, pp. 1040-1042, 0-7803-4403-0, Seattle, WA, USA, July 06-10, 1998, IEEE, New York

Urai, M.; Geshi, N. \& Staudacher, T. (2007). Size and volume evaluation of the caldera collapse on Piton de la Fournaise volcano during the April 2007 eruption using ASTER stereo imagery. Geophysical Research Letters, Vol.34, No.22, (November 2007) page numbers (L22318: 1-7), 0094-8276

Viola, P.A. \& Wells, W. (1995). Alignment by maximization of mutual information, Proceedings of the 5th International Conference on Computer Vision, pp. 6-23, 08186-7042-8, Cambridge, MA, USA, June 20-23, 1995, IEEE, New York

Vornberger, P.L. \& Bindschadler, R.A. (1992). Multispectral analysis of ice sheets using coregistered SAR and TM imagery. International Journal of Remote Sensing, Vol.13, No.4, (March 1992) page numbers (637-645), 0143-1161 
Wang, Y.L. \& Chen, Z. (2003). Automatic registration of SAR and optical images based on linear features and neural network, Proceedings of the 3rd International Symposium on Multispectral Image Processing and Pattern Recognition, pp. 553557, 0-8194-5181-9, Beijing, China, October 20-22, 2003, SPIE, Bellingham, WA, USA

Wegner, J.D. \& Soergel, U. (2008a). Bridge height estimation from combined high-resolution optical and SAR imagery. XXIth ISPRS Congress: Silk Road for Information from Imagery, Vol.XXXVII, No.B7, (July 2008) page numbers (1071-1076), 1682-1750

Wegner, J.D. \& Soergel, U. (2008b). Registration of SAR and optical images containing bridges over land, Proceedings of EARSeL Joint Workshop "Remote Sensing - New Challenges of High Resolution", pp. 194-201, 978-3-925143-79-3, Bochum, Germany, March 5-7, 2008, EARSeL, Bochum, Germany

Wu, Y.F. \& Maitre, H. (1990). A multiresolution approach for registration of a SPOT image and a SAR image, Proceedings of the 10th Annual International Geoscience and Remote Sensing Symposium: Remote Sensing Science for the Nineties, pp. 635-638, College Park, MD, USA, May 20-24, 1990, IEEE, New York

Yamaguchi, Y.; Kahle, A.B.; Tsu, H.; Kawakami, T. \& Pniel, M. (1998). Overview of advanced spaceborne thermal emission and reflectionradiometer (ASTER). IEEE Transactions on Geoscience and Remote Sensing, Vol.36, No.4, (July 1998) page numbers (1062-1071), 0196-2892

Yang, W.; Han, C.Z.; Sun, H. \& Cao, Y.F. (2005). Registration of high resolution SAR and optical images based on multiple features, Proceedings of the 25th IEEE International Geoscience and Remote Sensing Symposium (IGARSS 2005), pp. $3542-$ 3544, 0-7803-9050-4, Seoul, South Korea, July 25-29, 2005, IEEE, New York

Yoo, T.S. (Ed.) (2004). Insight into images: Principles and practice for segmentation, registration, and image analysis, A K Peters, Ltd., 1-5688-1217-5, Wellesley, Massachusetts, USA

Zamora, G.; Dickens, M. \& Mitra, S. (1998). A robust registration technique for multi-sensor images, Proceedings of 1998 IEEE Southwest Symposium on Image Analysis and Interpretation, pp. 87-90, 0-7803-4876-1, Tucson, AZ, USA, April 05-07, 1998, IEEE, New York

Zhang, D.R.; Yu, L. \& Cai, Z.G. (2007). Automatic registration for ASAR and TM images based on region features, Proceedings of the 15th International Conference on Geoinformatics, art. No. 675240, 978-0-8194-6912-0, Nanjing, China, May 25-27, 2007, SPIE, Bellingham, WA, USA

Zhang, Z.H.; Pan, C.H. \& Ma, S.D. (2004). An automatic method of coarse registration between multi-source satellite images, Proceedings of Intelligent Sensors, Sensor Networks and Information Processing Conference, pp. 205-209, 0-7803-8893-3, Melbourne, Australia, December 14-17, 2004, IEEE, New York

Zhao, Y. \& Chen, Y.Q. (2003). A robust contour model for matching synthetic aperture radar (SAR) images with maps, Proceedings of Conference on Image Processing and Pattern Recognition in Remote Sensing, pp. 150-161, 0-8194-4684-X, Hangzhou, China, October 25-27, 2002, SPIE, Bellingham, WA, USA

Zitova, B. \& Flusser, J. (2003). Image registration methods: A survey. Image and Vision Computing, Vol.21, No.11, (October 2003) page numbers (977-1000), 0262-8856 


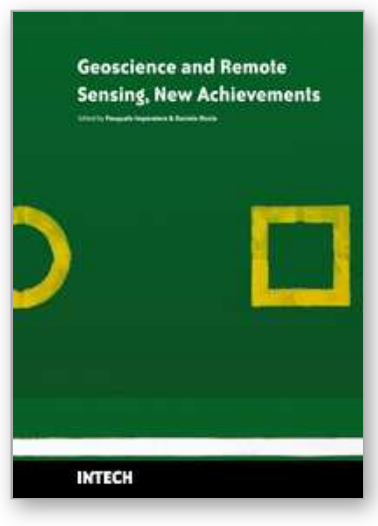

\author{
Geoscience and Remote Sensing New Achievements \\ Edited by Pasquale Imperatore and Daniele Riccio
}

ISBN 978-953-7619-97-8

Hard cover, 508 pages

Publisher InTech

Published online 01, February, 2010

Published in print edition February, 2010

Our planet is nowadays continuously monitored by powerful remote sensors operating in wide portions of the electromagnetic spectrum. Our capability of acquiring detailed information on the environment has been revolutionized by revealing its inner structure, morphology and dynamical changes. The way we now observe and study the evolution of the Earth's status has even radically influenced our perception and conception of the world we live in. The aim of this book is to bring together contributions from experts to present new research results and prospects of the future developments in the area of geosciences and remote sensing; emerging research directions are discussed. The volume consists of twenty-six chapters, encompassing both theoretical aspects and application-oriented studies. An unfolding perspective on various current trends in this extremely rich area is offered. The book chapters can be categorized along different perspectives, among others, use of active or passive sensors, employed technologies and configurations, considered scenario on the Earth, scientific research area involved in the studies.

\title{
How to reference
}

In order to correctly reference this scholarly work, feel free to copy and paste the following:

Qi Li, Bihong Fu and Yanfang Dong (2010). Registration of Radar and Optical Satellite Images Using Multiscale Filter Technique and Information Measure, Geoscience and Remote Sensing New Achievements, Pasquale Imperatore and Daniele Riccio (Ed.), ISBN: 978-953-7619-97-8, InTech, Available from: http://www.intechopen.com/books/geoscience-and-remote-sensing-new-achievements/registration-of-radarand-optical-satellite-images-using-multiscale-filter-technique-and-information

\section{INTECH}

open science | open minds

\section{InTech Europe}

University Campus STeP Ri

Slavka Krautzeka 83/A

51000 Rijeka, Croatia

Phone: +385 (51) 770447

Fax: +385 (51) 686166

www.intechopen.com

\section{InTech China}

Unit 405, Office Block, Hotel Equatorial Shanghai

No.65, Yan An Road (West), Shanghai, 200040, China 中国上海市延安西路65号上海国际贵都大饭店办公楼 405 单元

Phone: +86-21-62489820

Fax: +86-21-62489821 
(C) 2010 The Author(s). Licensee IntechOpen. This chapter is distributed under the terms of the Creative Commons Attribution-NonCommercialShareAlike-3.0 License, which permits use, distribution and reproduction for non-commercial purposes, provided the original is properly cited and derivative works building on this content are distributed under the same license. 